\title{
Telomerase reverse transcriptase gene amplification in hematological malignancies
}

\author{
Amany H. Abdelrahman 1* (D), Maha M. Eid², Mirhane Hassan', Ola M. Eid², Rania M. A. AbdelKader², \\ Nevin M. AlAzhary ${ }^{3}$, Rasha Y. Shahin ${ }^{4}$ and Mohamed T. Sallam ${ }^{5}$
}

\begin{abstract}
Background: Telomere is a complex DNA-protein structure located at the end of all eukaryotic chromosomes. The major role of human telomerase is to catalyze the addition of telomeric repeat sequences TTAGGG onto chromosome ends for stabilization of telomere length in attaining cellular immortality and may therefore be a critical step in carcinogenesis. Expression of significant levels of telomerase can dramatically increase proliferative life span and promote cellular immortality, thereby contributing to the malignant phenotype. The purpose of this study is to investigate telomerase reverse transcriptase (TERT) gene amplification in hematological neoplasms, e.g., multiple myeloma (MM), B-non-Hodgkin lymphoma (B-NHL), and acute myeloid leukemia (AML), using FISH technique and to evaluate its potential use as a prognostic marker.

Results: TERT amplification was detected in all groups of the participant patients (15 MM, $15 \mathrm{~B}-\mathrm{NHL}$, and $15 \mathrm{AML}$ patients), with higher incidence in AML patients (53.3\%). A significant association between the pattern of presentation and telomerase amplification was detected in $88.9 \%$ of the relapsed patients who demonstrated amplification of TERT. TERT amplification shows a significant association with p53 deletion and a highly significant association with poor prognosis.

Conclusions: TERT gene amplification is significantly associated with hematological malignancies and may play a critical role in carcinogenesis; thus, elucidation of their regulatory mechanism is highly demanding. Higher amplification was found in relapsed cases than de novo cases which highlight its potential implication in clinical analysis and disease monitoring. Moreover, our results suggest the future use of TERT gene as a potential prognostic marker that may aid in treatment decision and chemotherapy.
\end{abstract}

Keywords: hTERT gene, Multiple myeloma, Acute myeloid leukemia, B-NHL

\section{Background}

Telomeres are unique and genetically stable DNA-protein complex structure located at the ends of all eukaryotic chromosomes to preserve the genome integrity. It contains short non-coding tandem repeats (TTAGGG) that are extended by telomerase enzyme [1].

Telomerase is a ribonucleoprotein enzyme that is formed of two core components: catalytic subunit, human telomerase reverse transcriptase (hTERT), encoded by the

\footnotetext{
*Correspondence: amanyhosny123@yahoo.com

'Department of Clinical Pathology, National Research Center, El bohouth street, Cairo 12622, Egypt

Full list of author information is available at the end of the article
}

TERT gene (located at 5p15.33), telomerase RNA component (TERC) that acts as template for elongation of telomeres [2].

Every cell division is accompanied by shortening of telomere sequences resulting in an "end replication problem" which triggers the activation of DNA damage pathways leading to senescence and subsequent cell death. Telomere erosion and replicative senescence limit cellular proliferation, which is considered an essential tumor-suppressive mechanism [3, 4].

Telomerase expression actively maintains telomere length and hence is crucial for cellular proliferation and survival. Overexpression of telomerase plays an important 
role in the development of cancer, including hematological malignancies [3].

Since hTERT level is believed to be the rate limiting subunit of telomerase so unveiling the mechanisms behind its reactivation is a key step for the development of diagnostic and therapeutic applications [3].

The aim of this work is to investigate TERT gene amplification in hematological neoplasms using FISH technique and to evaluate its potential use as a prognostic marker.

\section{Methods}

\section{Study design}

This study was conducted on 45 patients recruited from the Internal Medicine Department, between April 2018 and January 2019. The study included 15 multiple myeloma patients, 15 B-non-Hodgkin lymphoma patients, and 15 patients with acute myeloid leukemia (30 male patients and 15 female patients); their age ranged from 38 to 78 years. Patients on treatment were excluded from this study.

The diagnosis of patients was established based on the WHO classification of hematolymphoid tumors [5], and prognosis evaluation was done according to the Revised International Staging System for multiple myeloma [6], International prognostic index of B-NHL [7], and WHO prognostic classification of AML [5].

\section{Clinical examination}

All patients were subjected to full history taking; clinical examination with special emphasis on the presence of lymphadenopathy, splenomegaly (SM), and hepatomegaly (HM); signs of anemia and thrombocytopenia; and abdominal ultrasonography for assessing organomegaly.

\section{Sampling}

Five milliliters of the venous blood sample was withdrawn from each participant under complete aseptic conditions for complete blood count $(\mathrm{CBC})$ and chemical test analysis. Also, $5 \mathrm{ml}$ bone marrow (BM) aspirate was collected and divided into an EDTA vacutainer for flow cytometric (FCM) analysis and a heparinized vacutainer for cytogenetics investigations.

\section{Laboratory investigations \\ $C B C$ analysis}

CBC was performed on an automatic cell counter Sysmex XS500 (Sysmex, Bohemia, New York, USA) with examination of Leishman-stained smears.

\section{Chemical test}

Measurement of serum level of albumin, calcium, and lactate dehydrogenase was performed on automated clinical chemistry analyzer (OLYMPUS AU400), assessment of different fractions of the serum proteins by serum protein electrophoresis.

\section{Immunophenotyping}

A flow cytometric immunophenotypic analysis was performed on the BM samples on the same day of their collection, using coulter EPICS-XL four-color flow cytometry (Coulter Diagnostic, Hialeah, FL, USA) using the following panels of monoclonal antibodies (all were supplied by Beckman Coulter, Fullerton, CA, USA).

For the diagnosis of MM: CD19, CD20, CD27, CD28, CD33, CD81, and cyt $\mathrm{k}$ light chain (all are fluorescein isothiocyanate labeled) and CD10, CD13, CD38, CD56, CD117, CD200, and $\lambda$ light chain (all are labeled by phycoerythrin). Gating was done using phycoerythrincyanine-5-labeled CD138 for plasma cells.

For the diagnosis of B-NHLs: CD19, HLA-DR, CD20, CD22, CD23, FMC7, CD103, and $\mathrm{k}$ light chain (all are fluorescein isothiocyanate labeled) and CD5, CD10, CD11C, CD25, CD38, CD52, and $\lambda$ light chain (all are labeled by phycoerythrin). Gating was done using phycoerythrin-cyanine-5-labeled CD19, and clonality was assessed using $\kappa$ and $\lambda$ light chains expressed on CD19+ cells.

For the diagnosis of AML: CD19, CD20, CD33, HLA$\mathrm{DR}, \mathrm{CD} 15$, and MPO (all are fluorescein isothiocyanate labeled) and CD34, CD10, TDT, CD38, CD13, CD117, CD5, CD7, CD56, and CD79A (all are labeled by phycoerythrin). Gating was done using phycoerythrin-cyanine5-labeled CD45.

\section{Cytogenetics investigations}

Cytogenetics investigations included:

\section{a) Conventional cytogenetics}

Heparinized bone marrow was cultured using complete culture media without phytohemagglutinin for $24 \mathrm{~h}$ and $48 \mathrm{~h}$. The cytogenetic preparation and G-banding were done according to routine laboratory procedures according to Verma and Babu [8].

Patients with one or two independent cytogenetic aberrations were regarded as having simple aberrations, whereas those with three or more independent aberrations were regarded as having multiple aberrations.

b) Fluorescence in situ hybridization (FISH) technique: using selected probes LSI hTERT (5p15), p53 (17p13.1) gene, LSI IGH (14q32) break apart rearrangement, and LSI 13q14.3 (Vysis, London, UK)

The heparinized BM samples were cultured using complete culture media without phytohemagglutinin, incubated at $37^{\circ} \mathrm{C}$ for 2 days, then harvested as described 
previously by Schlette et al. [9]. FISH was carried out according to the manufacturer's instructions, and examination of at least 200 interphase cells was conducted using Cytovision software (Leica, NJ, USA).

\section{Statistical analysis}

All of the statistical calculations were made using the excel program and SPSS, version 18 program (SPSS Inc., Chicago, IL, USA). Qualitative data were presented as frequency and percentage, and quantitative parametric data were presented as mean and standard deviation (SD). Association between parameters was done by Pearson chi square. An effect was considered statistically significant at $p$ value less than 0.05 and highly significant at $p$ value less than 0.01 .

\section{Results}

Demographic, laboratory, and cytogentics features of the studied groups

The study included 45 patients suffering from different hematologic malignancies classified as follows: group I, group II, and group III.

Group I

- This group included $15 \mathrm{MM}$ patients (12 newly diagnosed and 3 relapsed cases), and their age ranged between 55 and 78 years with a mean of 68.2 years. They were 12 males (80\%) and 3 females (20\%), with a male to female ratio of 4:1.

- Karyotyping of BM was performed for all patients and showed normal karyotype except for one case (6.7\%) that had monosomy 13.

- FISH analysis was successfully performed on the 15 BM samples. p53 deletion was detected in 4 patients (26.7\%) and $14 \mathrm{q} 32$ rearrangement was detected in 3 patients (20\%), while 13q14.3 deletion was detected in 5 patients (33.3\%).

- TERT gene amplification was detected in 3 patients (20\%). The percent of cells with amplification

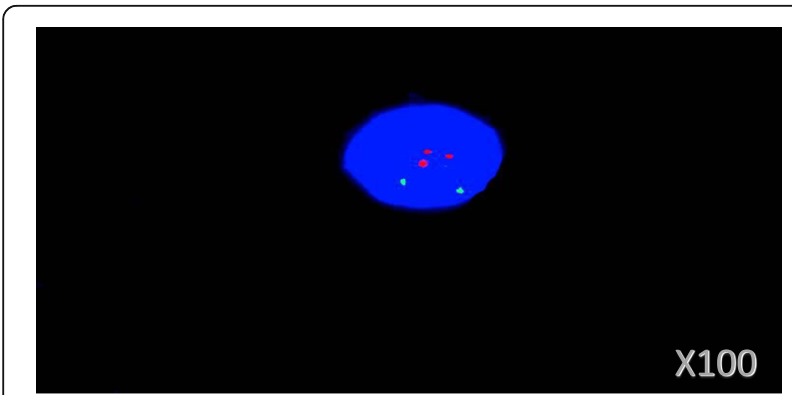

Fig. 1 FISH using hTERT (5p15) spectrum red and control on 5(q)spectrum green show amplification of hTERT (three red signals) in the interphase nucleus from MM patient
Table 1 Descriptive data of multiple myeloma patients (group I)

\begin{tabular}{|c|c|}
\hline Parameter & MM patients $(N=15)$ \\
\hline Age (mean \pm SD) & $68.2 \pm 6.8$ \\
\hline \multicolumn{2}{|l|}{ Gender, N (\%) } \\
\hline Male & $12(80 \%)$ \\
\hline Female & $3(20 \%)$ \\
\hline \multicolumn{2}{|l|}{ Presentation, N (\%) } \\
\hline DNV & $12(80 \%)$ \\
\hline Relapse & $3(20 \%)$ \\
\hline Lymphadenopathy, N (\%) & $2(13.3 \%)$ \\
\hline Splenomegaly, N (\%) & $2(13.3 \%)$ \\
\hline Hepatomegaly, N (\%) & $1(6.7 \%)$ \\
\hline WBC count $\left(\times 10^{9} / 1\right)($ mean $\pm S D)$ & $9 \pm 5.2$ \\
\hline Hb level (g/dl) (mean \pm SD) & $10.5 \pm 2.1$ \\
\hline Platelet count $\left(\times 10^{9} / I\right)($ mean \pm SD) & $146.5 \pm 8.5$ \\
\hline BM plasma cells\% (mean \pm SD) & $51.6 \pm 14$ \\
\hline \multicolumn{2}{|l|}{ Albumin level, $N(\%)$} \\
\hline$<3.5 \mathrm{~g} / \mathrm{dl}$ & $9(60 \%)$ \\
\hline$\geq 3.5 \mathrm{~g} / \mathrm{dl}$ & $6(40 \%)$ \\
\hline \multicolumn{2}{|l|}{$\beta 2$ microglobulin } \\
\hline$<3.5 \mathrm{mg} / \mathrm{l}$ & $5(33.3 \%)$ \\
\hline$\geq 3.5 \mathrm{mg} / \mathrm{l}$ & $10(66.7 \%)$ \\
\hline Lactate dehydrogenase $(\mathrm{U} / \mathrm{L})($ mean $\pm \mathrm{SD})$ & $286.7 \pm 66$ \\
\hline \multicolumn{2}{|l|}{ Corrected calcium } \\
\hline$<10.5 \mathrm{mg} / \mathrm{dl}$ & $11(73.3 \%)$ \\
\hline$\geq 10.5 \mathrm{mg} / \mathrm{dl}$ & $4(26.7 \%)$ \\
\hline \multicolumn{2}{|l|}{ Protein electrophoresis, N (\%) } \\
\hline Monoclonal gammopathy & $6(40 \%)$ \\
\hline Hypergammaglobulinemia & $1(6.7 \%)$ \\
\hline Hypoalbuminemia & $3(20 \%)$ \\
\hline Normal & $5(33.3 \%)$ \\
\hline \multicolumn{2}{|l|}{ Karyotype, N (\%) } \\
\hline Normal & $14(93.3 \%)$ \\
\hline Numerical aberrations & $1(6.7 \%)$ \\
\hline P53 (17p13.1) deletion, $N(\%)$ & $4(26.7 \%)$ \\
\hline 14q32 rearrangement, $N(\%)$ & $3(20 \%)$ \\
\hline 13q14.3 deletion, $N(\%)$ & $5(33.3 \%)$ \\
\hline TERT amplification, N (\%) & $3(20 \%)$ \\
\hline \multicolumn{2}{|l|}{ Prognosis, N (\%) } \\
\hline । & $6(40 \%)$ \\
\hline$\|$ & $1(6.6 \%)$ \\
\hline III & $8(53.3 \%)$ \\
\hline
\end{tabular}

$B M$ bone marrow, DNV de novo, $H b$ hemoglobin, TERT telomerase reverse transcriptase, $W B C s$ white blood cells 
ranged from 25 to $60 \%$. The no. of copies ranged from 3 to 5 copies (Fig. 1).

The descriptive and cytogenetics data of MM patients are presented in Tables 1 and 2 .

Group II

- This group included 15 B-NHL patients (12 newly diagnosed and 3 relapsed cases), and their age ranged between 52 and 78 years with a mean of 64.3 years. They were 9 males (60\%) and 6 females (40\%), with a male to female ratio of $1.5: 1$.

- Karyotyping of BM samples was performed for all patients and showed that 8 cases (53.3\%) had normal karyotype, 5 cases (33.3\%) had numerical aberration, and 2 cases (13.3\%) had structural abnormalities.

- FISH analysis was successfully performed on the 15 BM samples and p53 deletion was detected in 5 patients (33.3\%) while $14 \mathrm{q} 32 \mathrm{R}$ was detected in 3 patients (20\%).

- TERT gene amplification was detected in 7 cases (46.7\%). The percent of cells with amplification ranged from 14 to $40 \%$. The no. of copies ranged from 2 to 4 copies.

- The descriptive and cytogenetics data of B-NHL patients are presented in Tables 3 and 4.

\section{Group III}

- This group included 15 AML patients (11 newly diagnosed and 4 relapsed cases), and their age ranged between 38 and 68 years with a mean of 47.2 years. They were 9 males (60\%) and 6 females (40\%), with a male to female ratio of 1.5:1.

- Karyotyping of BM samples was performed for all patients and showed that 8 patients (53.3\%) had normal karyotype, 4 patients (26.7\%) had numerical aberration, and 3 patients (20\%) had structural abnormalities.

- FISH analysis was performed on the $15 \mathrm{BM}$ samples. TERT gene amplification was detected in 8 patients (53.3\%). The percent of cells with amplification ranged from 20 to $72 \%$. The no. of copies ranged from 2 to 5 copies (Fig. 2).

- The descriptive and cytogenetics data of AML patients are presented in Tables 5 and 6 .

Our results showed that TERT amplification was detected in all groups of the participant patients with higher incidence in AML patients; 8 patients (53.3\%) showed amplification, while the least percentage was detected in MM; 3 patients (20\%) and 7 patients with BNHL (46.7\%) showed amplification of the TERT.

Regarding the clinical presentation, a significant association was detected between the pattern of presentation and telomerase amplification $(p<0.05), 8$ cases of the relapsed patients (80\%) demonstrate amplification of TERT, while 24 patients with DNV presentation (68.6\%) showed no TERT amplification.

In the association analysis presented in Table 7, TERT gene amplification shows a significant association with splenomegaly $(p<0.05)$. However, both hepatomegaly and lymphadenopathy show no significant association with telomerase amplification $(p>0.05)$.

Table 2 Cytogenetics results of multiple myeloma patients (group I)

\begin{tabular}{llllll}
\hline & Karyotype & P53 del & 14q32R & $13 q 14.3$ del & TERT ampl \% of cells \\
\hline 1 & $46, x y$ & $30 \%$ & Negative & $20 \%$ & Negative \\
3 & $46, x y$ & Negative & $25 \%$ & Negative & Negative \\
4 & Negative & Negative & Negative & Negative \\
5 & $46, x y$ & Negative & Negative & $27 \%$ & $60 \%$ \\
6 & $46, x y$ & Negative & Negative & Negative \\
7 & $46, x y$ & Negative & Negative & $40 \%$ & Negative \\
8 & $46, x x$ & Negative & Negative & Negative & Negative \\
9 & $46, x y$ & Negative & $30 \%$ & $25 \%$ \\
10 & $45, x x,-13$ & Negative & Negative & Negative \\
11 & $46, x y$ & Negative & Negative & Negative \\
12 & $46, x y$ & Negative & $32 \%$ & Negative & Negative \\
13 & $46, x x$ & Negative & Negative & $20 \%$ & Negative \\
14 & $46, x y$ & Negative & Negative & Negative & $40 \%$ \\
15 & $46, x y$ & Negative & Negative & Negative \\
\hline
\end{tabular}


Table 3 Descriptive data of B-non-Hodgkin lymphoma patients

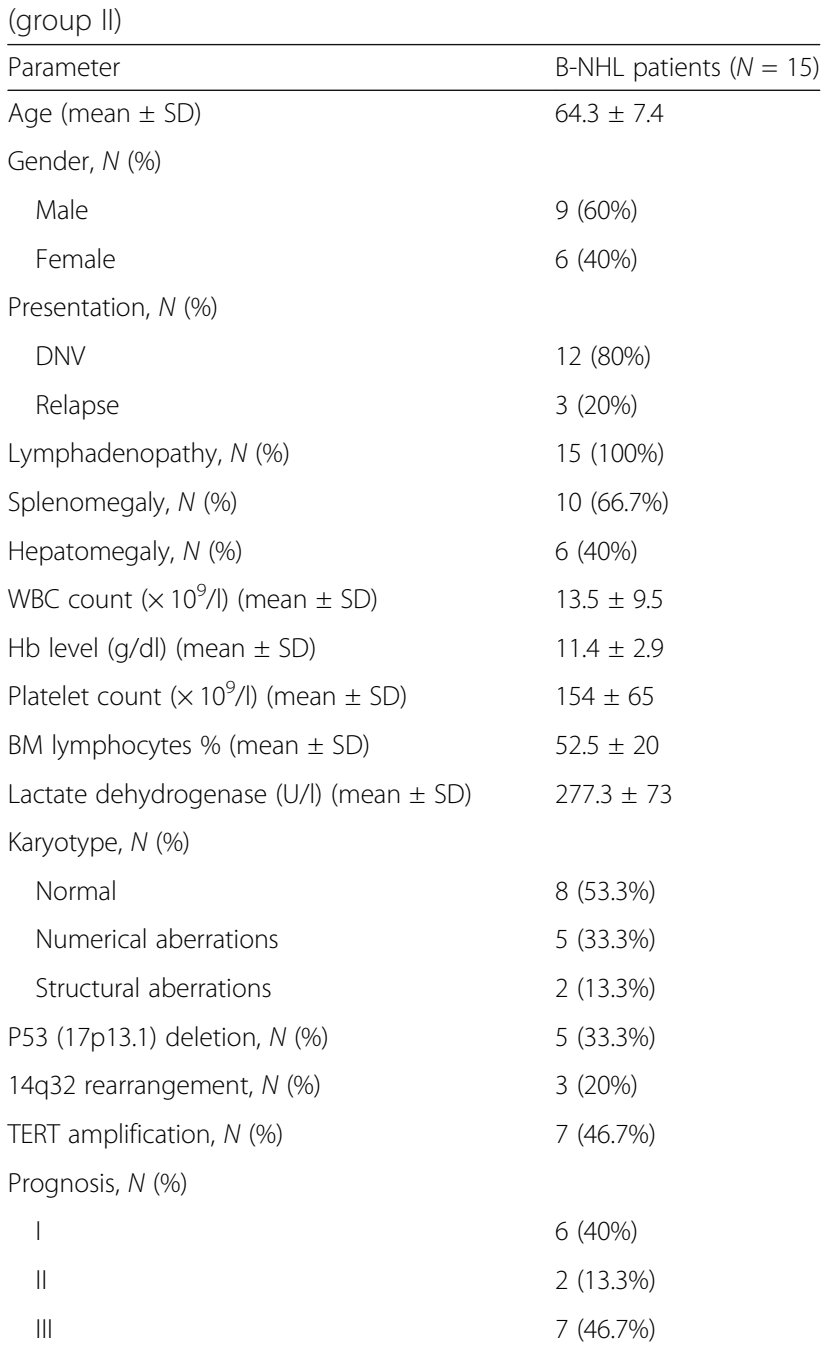

$B M$ bone marrow, DNV de novo, $H b$ hemoglobin, TERT telomerase reverse transcriptase, WBCs white blood cells

As regards the chromosomal aberrations, conventional karyotype analysis revealed no significant association with TERT amplification $(p>0.05)$.

Results by FISH technique show a significant association between $\mathrm{p} 53$ deletion and TERT amplification $(p<$ $0.05) ; 6$ patients with p53 deletion $(66.7 \%)$ showed TERT amplification, while only 4 patients (19\%) without the deletion had amplification of the TERT.

On the other hand, no association could be detected between both $13 \mathrm{q} 14.3$ deletion and $14 \mathrm{q} 32$ rearrangement with TERT amplification $(p>0.05)$.

A highly significant association was detected between the bad prognosis and TERT amplification $(p<0.001)$. Twelve patients considered as having bad prognosis had TERT amplification (63.2\%), while 16 patients considered as having good prognosis had no TERT amplification $(80 \%)$.
Finally, no significant association was detected between TERT amplification with age, sex, white blood cell (WBC) count, hemoglobin ( $\mathrm{Hb})$ level, and platelet count $(p>0.05)$.

\section{Discussion}

Gene amplification is a common genomic disorder in malignant cells which results in an increase of encoded protein synthesis [10]. The association of increased amplification of TERT with the activation of telomerase activity has been anticipated. High telomerase activity is usually observed in germ line cells and most cancer cells, while it is either undetectable or present in very low levels in normal human somatic cells [11].

Increased telomerase activity detected in more than $90 \%$ of all cancers correlates with resistance to senescence and apoptosis, immortalization, and elongation of telomere [12]. Therefore, its crucial role in tumor formation has been considered. Furthermore, genetic variants and somatic alterations in the TERT gene may disturb telomerase function and is involved in cancer development as well as the outcome of chemotherapy [3].

In several cases, chromosomal break points were detected nearby the TERT promoter, which suggested that chromosomal rearrangements might be responsible of either relieving the promoter from its suppressive epigenetic environment or placing it close to enhancers at different chromosomal sites [13, 14]. The telomerase reverse transcriptase-cleft lip and palate transmembrane protein 1-like protein (TERT-CLPTM1L) locus containing the gene encoding TERT gene is commonly exposed to somatic chromosomal translocations of immunoglobulin heavy (IGH) and non-IG loci in B cell neoplasms, like in mantle cell lymphoma and splenic marginal zone lymphoma. Additionally, higher TERT transcriptional expression as well as increased telomerase activity were noticed in tumors bearing chromosomal aberrations involving TERT gene $[15,16]$.

Our results showed that TERT amplification was detected in all studied groups and this is in agreement with several previous studies. In studies done by Nowak et al. [11] and Eid et al. [17], amplification of TERC and TERT genes were detected by FISH technique in $90.4 \%$ and $100 \%$ (respectively) of AML patients. They suggested that the activation of telomerase in leukemic cells is linked to the amplification of TERC and TERT genes and that the high expression and activity of telomerase spotted in leukemic cells can be clarified by the amplification of these genes. Furthermore, they suggested the possible use of telomerase activity to discriminate malignant from normal cells and that telomerase itself may work as diagnostic marker for tumor development. Moreover, previous studies by Aalbers et al. and Yan et al. $[18,19]$ reported that genetic alterations causing 
Table 4 Cytogenetics results of B-non-Hodgkin lymphoma (group II)

\begin{tabular}{|c|c|c|c|c|c|}
\hline & Karyotype & P53 deletion & $14 q$ rearrangement & $\%$ of cell TERT amplification & Range of copy number \\
\hline 1 & $47, X X,+12$ & Negative & Negative & Negative & \\
\hline 2 & $46, x x, i(8)(q 10)$ & $24 \%$ & Negative & Negative & \\
\hline 3 & $46, x y$ & Negative & Negative & Negative & \\
\hline 4 & $46, x x$ & Negative & Negative & Negative & \\
\hline 5 & $46, x y$ & Negative & $18 \%$ & Negative & \\
\hline 6 & $47, x y,+5$ & Negative & Negative & $35 \%$ & $2-3$ \\
\hline 7 & $46, x y$ & Negative & Negative & $14 \%$ & $2-3$ \\
\hline 8 & $45, x y,-17$ & $50 \%$ & Negative & $25 \%$ & $3-4$ \\
\hline 9 & $46, x y$ & $20 \%$ & $15 \%$ & $33 \%$ & $2-3$ \\
\hline 10 & $46, x y$ & Negative & Negative & Negative & \\
\hline 11 & $46, x x, t(X ; 11)(q 10 ; q 10)$ & $18 \%$ & Negative & $18 \%$ & $3-4$ \\
\hline 12 & $48, x x,+3,+12$ & $25 \%$ & Negative & $40 \%$ & $2-3$ \\
\hline 13 & $46, x x$ & Negative & Negative & Negative & \\
\hline 14 & 47,xy,+marker & Negative & $15 \%$ & $30 \%$ & $3-4$ \\
\hline 15 & $46, x y$ & Negative & Negative & Negative & \\
\hline
\end{tabular}

increased telomerase activity have been implicated in many bone marrow failure syndromes like AML that induced an expansion of undifferentiated myeloid hematopoietic stem cell progenitors.

Several publications reported telomerase activity in B cell malignant lymphomas. In these studies, a positive correlation of telomerase activity with the rate of proliferation in different subtypes of B cell NHLs as well as lymphoid cell lines was observed, suggesting the role of TERT deregulation in lymphomagenesis [20].

A previous study by $\mathrm{Xu}$ et al. [21] reported high telomerase activity in MM patients and all cases with plasma cell leukemia. On the other hand, telomerase levels were not elevated in patients with monoclonal gammopathy of undetermined significance (MGUS). However, Panero et al. [20] have found increased expression levels of TERT, in MM as well as in MGUS. Remarkably, in both diseases, the patients displaying the highest telomerase transcription

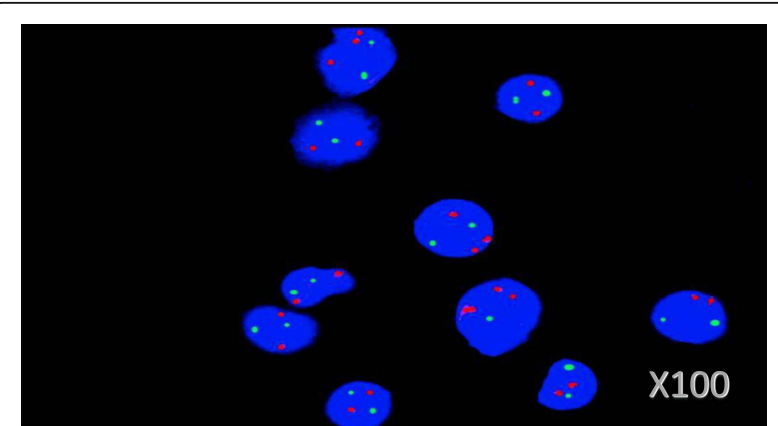

Fig. 2 FISH using hTERT (5p15) spectrum red and control on 5(q)spectrum green show amplification of hTERT (three red signals) in three interphase nuclei from AML patient
Table 5 Descriptive data of acute myeloid leukemia patients (group III)

\begin{tabular}{|c|c|}
\hline Parameter & AML patients $(N=15)$ \\
\hline Age (mean \pm SD) & $47.2 \pm 7.5$ \\
\hline \multicolumn{2}{|l|}{ Gender, N (\%) } \\
\hline Male & $9(60 \%)$ \\
\hline Female & $6(40 \%)$ \\
\hline \multicolumn{2}{|l|}{ Presentation, N (\%) } \\
\hline DNV & $11(73.3 \%)$ \\
\hline Relapse & $4(26.7 \%)$ \\
\hline Lymphadenopathy, N (\%) & $8(53.3 \%)$ \\
\hline Splenomegaly, N (\%) & $4(26.7 \%)$ \\
\hline Hepatomegaly, N (\%) & $3(20 \%)$ \\
\hline WBC count $\left(\times 10^{9} / \mathrm{l}\right)($ mean $\pm \mathrm{SD})$ & $8.8 \pm 5.9$ \\
\hline Hb level (g/dl) (mean \pm SD) & $11.3 \pm 2.4$ \\
\hline Platelet count $\left(\times 10^{9} / \mathrm{l}\right)($ mean $\pm \mathrm{SD})$ & $110 \pm 38$ \\
\hline BM blasts \% (mean \pm SD) & $68 \pm 21$ \\
\hline \multicolumn{2}{|l|}{ Karyotype, N (\%) } \\
\hline Normal & $8(53.3 \%)$ \\
\hline Numerical aberrations & $4(26.7 \%)$ \\
\hline Structural aberrations & $3(20 \%)$ \\
\hline TERT amplification, N (\%) & $8(53.3 \%)$ \\
\hline \multicolumn{2}{|l|}{ Prognosis, $N(\%)$} \\
\hline Good & $8(53.3 \%)$ \\
\hline Intermediate & $3(20.1 \%)$ \\
\hline Bad & $4(26.6 \%)$ \\
\hline
\end{tabular}

$B M$ bone marrow, DNV de novo, $H b$ hemoglobin, TERT telomerase reverse transcriptase, WBCs white blood cells 
Table 6 Cytogenetics results of acute myeloid leukemia (group

\begin{tabular}{llll} 
III) & & $\begin{array}{l}\text { \% of cell TERT } \\
\text { amplification }\end{array}$ & $\begin{array}{l}\text { Range of copy } \\
\text { number }\end{array}$ \\
\hline 1 & $46, x x$ & $25 \%$ & $3-4$ \\
2 & $46, x y$ & Negative & \\
3 & $46, x y$ & $30 \%$ & $3-4$ \\
4 & $47, x y,+8$ & $25 \%$ & $2-3$ \\
5 & $46, x y$ & Negative & \\
6 & $46, x x, t(8 ; 21)(q 22 ; q 22)$ & Negative & \\
7 & $46, x x$ & Negative & \\
8 & $46, x x$ & $33 \%$ & $2-3$ \\
9 & $46, x y$ & Negative & \\
10 & $45, x,-y$ & Negative & \\
11 & $47, x x,+8$ & $20 \%$ & $2-3$ \\
12 & $46, x y, t(8 ; 21)(q 22 ; q 22)$ & $38 \%$ & $3-5$ \\
13 & $46, x y, t(15 ; 17)$ & Negative & \\
14 & $46, x x$ & $72 \%$ & $3-4$ \\
15 & $47, x y,+8$ & $38 \%$ & $2-3$ \\
\hline & & &
\end{tabular}

levels had the shortest telomere length (TL). Diaz de la Guardia et al. [22] demonstrated by gene expression arrays that TERT along with other 16 genes are directly responsible for TL maintenance in MM cells. They even reported higher expression levels of these genes than those in human embryonic stem cells and induced pluripotent stem cells, which have indefinite proliferation capacity [20].

The significant association observed between TERT amplification and bad prognosis is in agreement with previous studies by Röth et al. [23] and Vicente-Dueñas et al. [24] who reported that telomerase activity is not required for the initiation of AML and B cell neoplasm, but it is required for their maintenance. Besides, they stated that enhanced telomerase activity was linked to disease progression, chemotherapy resistance, and worse prognosis in patients with hematologic neoplasia. In addition, telomere shortening could be induced in leukemia cell lines leading eventually to proliferative arrest or cellular apoptosis in vitro and in vivo. The observed functional necessity of telomerase in established hematologic neoplasms offers a basis to therapeutically target telomerase in these diseases [20, 25].

The significant association observed between TERT amplification and p53 deletion is in accordance with Boldrini et al. [26]. They found that altered P53 gene

Table 7 Association between TERT gene amplification and clinicopathological and cytogenetic characteristics of all patients

\begin{tabular}{|c|c|c|c|}
\hline Variables & TERT amplification negative & TERT amplification positive & $p$ value \\
\hline Age (mean \pm SD) & $58.6 \pm 11.7$ & $61.5 \pm 11.7$ & 0.4 \\
\hline Sex & & & 0.52 \\
\hline Male & 19 & 11 & \\
\hline Female & 8 & 7 & \\
\hline Presentation at the time of diagnosis & & & 0.0008 \\
\hline DNV & 26 & 10 & \\
\hline Relapse & 1 & 8 & \\
\hline Hepatomegaly & 3 & 7 & 0.08 \\
\hline Splenomegaly & 4 & 12 & 0.004 \\
\hline Lymphadenopathy & 12 & 13 & 0.3 \\
\hline WBC count (mean $\pm \mathrm{SD})\left(\times 10^{3} / \mu \mathrm{l}\right)$ & $11.03 \pm 7.6$ & $9.61 \pm 9.8$ & 0.59 \\
\hline Hb level (mean $\pm \mathrm{SD})(\mathrm{g} / \mathrm{dl})$ & $11.39 \pm 2.68$ & $10.69 \pm 2.3$ & 0.36 \\
\hline Platelet count (mean $\pm \mathrm{SD})\left(\times 10^{3} / \mu \mathrm{l}\right)$ & $147.2 \pm 80.4$ & $124 \pm 48.5$ & 0.26 \\
\hline Chromosomal aberrations by conventional karyotype & 6 & 9 & 0.052 \\
\hline $13 q 14.3$ deletion & 3 & 2 & 0.2 \\
\hline $14 q 32$ rearrangement & 4 & 2 & 1 \\
\hline P53(17p13.1) deletion & 3 & 6 & 0.011 \\
\hline Prognosis & & & 0.021 \\
\hline Good (I) & 16 & 4 & \\
\hline Intermediate (II) & 4 & 2 & \\
\hline Bad (III) & 7 & 12 & \\
\hline
\end{tabular}

DNV de novo, $H b$ hemoglobin, TERT telomerase reverse transcriptase, WBCs white blood cells 
detected in patients with colorectal cancer was significantly associated with both high telomerase activity and increase hTERT expression, suggesting a role of p53 in the signaling pathway for telomerase control. Also, Gonza'lez-Sua'rez et al. [27] suggested the concomitant association between loss of the p53 tumor suppressor and high telomerase activity in inducing tumors during the normal aging process in the mouse.

A previous study done by Rahman et al. [28] reported that the role of p53 in downregulating hTERT may be crucial for the p53-dependent elimination of tumor cells that already express high levels of hTERT. Moreover, p53 inactivation exerted by different mechanisms in tumors may aid in the activation of hTERT and thus contribute to the unlimited replicative potential of tumor cells. Kanaya et al. [29] explained that hTERT could be repressed in tumor cells by $\mathrm{p} 53$ through interaction with $\mathrm{Sp} 1$ protein or other transcription factors involved in this regulation.

\section{Conclusions}

Our data showed that TERT gene amplification is significantly associated with hematological malignancies and may play a critical role in carcinogenesis; thus, elucidation of their regulatory mechanism is highly demanding. Moreover, the highly significant association of TERT amplification and poor prognosis may suggest further use of TERT gene as a potential prognostic marker that may aid in treatment decision and chemotherapy.

\section{Abbreviations}

AML: Acute myeloid leukemia; BM: Bone marrow; CBC: Complete blood count; DNV: De novo; FCM: Flow cytometry; FISH: Fluorescence in situ hybridization; Hb: Hemoglobin; HM: Hepatomegaly; hTERT: Human telomerase reverse transcriptase; IGH: Immunoglobulin heavy; LN: Lymph node; MGUS: Monoclonal gammopathy of undetermined significance; MM: Multiple myeloma; NHL: Non-Hodgkin lymphoma; SD: Standard deviation; SM: Splenomegaly; TERC: Telomerase RNA component; TERTCLPTM1L: Telomerase reverse transcriptase-cleft lip and palate transmembrane protein 1-like protein; TL: Telomere length; WBC: White blood cell
\end{abstract}

\section{Acknowledgements}

We would like to express our gratitude to the National Research Centre and Faculty of Medicine, Ain Shams University, for giving us the chance to accomplish this study with the help of its competent technicians and updated equipment and instrumentation.

\section{Authors' contributions \\ $\mathrm{AH}$ participated in preparing the design of the research, conducting the laboratory work, and preparing the paper for submission and final approval of the version to be published. MT participated in the diagnosis of the patients and conducting the laboratory work. $\mathrm{MH}$ participated in performing the laboratory work and preparing the paper for submission. NM participated in performing the laboratory work and statistical analysis. MM participated in preparing the design of the research, conducting the cytogenetics work, and preparing the paper for submission. OM participated in conducting the cytogenetics work and helped to draft the manuscript. RM participated in performing the cytogenetics work and statistical analysis. RY was responsible for the proper selection and diagnosis of the patients. All authors read and approved the final manuscript.}

\section{Availability of data and materials}

Data and material are available upon request.

\section{Ethics approval and consent to participate}

The study was approved by the ethical committee of the National Research Center (18074), which is in accordance with the ethical standards of the

Declaration of Helsinki. All participants gave informed written consent before their inclusion in the study.

\section{Consent for publication}

If the paper is accepted by the Egyptian Journal of Medical Human Genetics, the study will not be published elsewhere in the same form in English or any other language, and all authors are in agreement with the content of the manuscript.

\section{Competing interests}

The authors declare that they have no competing interests.

\section{Author details}

${ }^{1}$ Department of Clinical Pathology, National Research Center, El bohouth street, Cairo 12622, Egypt. ${ }^{2}$ Department of Human Cytogenetics, National Research Center, Cairo, Egypt. ${ }^{3}$ Department of Clinical Pathology, National Cancer Institute, Cairo University, Cairo, Egypt. ${ }^{4}$ Department of Internal Medicine, Faculty of Medicine, Ain Shams University, Cairo, Egypt.

${ }^{5}$ Department of Clinical Pathology, Faculty of Medicine, Ain Shams University, Cairo, Egypt.

Received: 3 July 2019 Accepted: 25 October 2019

Published online: 29 November 2019

\section{References}

1. Gaspar T, Sá A, Lopes M, Sobrinho-Simões M, Soares P, Vinagre J (2018) (2018). Telomere maintenance mechanisms in cancer. Genes 9:241-299

2. Jafri A, Ansari A, Alqahtani H, Shay W (2016) Roles of telomeres and telomerase in cancer, and advances in telomerase-targeted therapies. Genome Med. 8:69-87

3. Ropio J, Merlio J, Soares P, Chevret E (2016) Telomerase activation in hematological malignancies. Genes 7:61-74

4. Wang K, Wang L, Liu J, Zhou J, Li X, Hu W, Jiang J, Hao B (2018) The prognostic significance of hTERT overexpression in cancers: a systematic review and meta-analysis. Medicine (Baltimore) 97:e11794

5. Muller-Hermelink HK, Montserrat E, Catovsky D, Campo E, Harris NL, Stein H (2008) Chronic lymphocytic leukemia/small lymphocytic lymphoma. In: World Health Organization. Classification of tumours of haematopoietic and lymphoid tissues. 4th ed. IARC Press, Lyon

6. Palumbo A, Avet-Loiseau H, Oliva S, Lokhorst M, Goldschmidt H, Rosinol L, Richardson P, Caltagirone S, Lahuerta J et al (2015) Revised International Staging System for multiple myeloma: a report from International Myeloma Working Group. J Clin Oncol. 33:2863-2869

7. Ziepert M, Hasenclever D, Kuhnt E, Glass B, Schmitz N, Pfreundschuh M, Loeffler M (2010) Standard international prognostic index remains a valid predictor of outcome for patients with aggressive CD20+ B-cell lymphoma in the rituximab era. J Clin Oncol. 28:2373-2380

8. Verma S, Babu A (1995) Human chromosomes. Principles and techniques, 2nd edn. McGraw-Hill, New York

9. Schlette E, Bueso-Ramos C, Giles F, Glassman A, Hayes K, Medeiros L (2001) Mature B-cell leukemias with more than $55 \%$ prolymphocytes: a heterogeneous group that includes an unusual variant of mantle cell lymphoma. Am J ClinPathol 115:571-581

10. Albertson D (2006) Gene amplification in cancer. Trends Genet. 22:447-455

11. Nowak T, Januszkiewicz D, Zawada M, Pernak M, Lewandowski K, Rembowska J, Nowicka K, Mankowski P, Nowak J (2006) Amplification of hTERT and hTERC genes in leukemic cells with high expression and activity of telomerase. Oncol Rep 16(2):301-305

12. Mosrati M, Willander $K$, Falk I, Hermanson M, Höglund M, Stockelberg D, Wei Y, Lotfi K, Söderkvist P (2015) Association between TERT promoter polymorphisms and acute myeloid leukemia risk and prognosis. Oncotarget 6:25109-25120

13. Zhao Y, Wang S, Popova Y, Grigoryev A, Zhu J (2009) Rearrangement of upstream sequences of the hTERT gene during cellular immortalization. Genes Chromosom. Cancer 48:963-974 
14. Zhang A, Zheng C, Lindvall C, Hou M, Ekedahl J, Lewensohn R, Yan Z, Yang $X$, Henriksson M, Blennow E (2000) Frequent amplification of the telomerase reverse transcriptase gene in human tumors. Cancer Res. 60:6230-6235

15. Nagel I, Szczepanowski M, Martín-Subero I, Harder L, Akasaka T, Ammerpohl O, Callet-Bauchu E, Gascoyne D, Gesk S, Horsman D (2010) Deregulation of the telomerase reverse transcriptase (TERT) gene by chromosomal translocations in B-cell malignancies. Blood 116:1317-1320

16. Schilling $G$, Penas $M$, Janjetovic $S$, Oliveira-Ferrer $L$, Braig $M$, Behrmann $P$, Bokemeyer C, Dierlamm J (2013) Molecular characterization of chromosomal band 5p15. 33: a recurrent breakpoint region in mantle cell lymphoma involving the TERT-CLPTM1L locus. Leuk. Res. 37:280-286

17. Eid M, Helmy N, Omar I, Mohamed A, El Sewefy D, Fadel I, Helal R (2013) Clinical significance of telomerase genes (hTERC And hTERT) amplification in patients with acute myeloid leukemia. G.J.O 13:51-60

18. Aalbers M, Calado T, Young S, Zwaan M, Wu C, Kajigaya S (2013) Telomere length and telomerase complex mutations in pediatric acute myeloid leukemia. Leukemia. 27:1786-1795

19. Yan S, Han B, Wu Y, Zhou D, Zhao Y (2013) Telomerase gene mutation screening and telomere overhang detection in Chinese patients with acute myeloid leukemia. Leuk Lymphoma. 54:1437-1441

20. Panero J, Dos Santos P, Slavutsky I (2017) Telomere protein complexes and their role in lymphoid malignancies. Frontiers Biosci 9:17-30

21. Xu D, Zheng C, Bergenbrant S, Holm G, Björkholm M, Yi Q, Gruber A (2001) Telomerase activity in plasma cell dyscrasias. Br J Cancer 84:621-625

22. De la Guardia R D, Catalina P, Panero J, Elosua C, Pulgarin A, López B, Ayllón V, Ligero G, Slavutsky I, Leone E (2012) Expression profile of telomereassociated genes in multiple myeloma. J Cell Mol Med 16:3009-3021

23. Röth A, Vercauteren S, Sutherland J, Lansdorp M (2003) Telomerase is limiting the growth of acute myeloid leukemia cells. Leukemia 17:2410-2417

24. Vicente-Dueñas C, Barajas-Diego M, Romero-Camarero I, González-Herrero I, Flores T, Sánchez-García I (2012) Essential role for telomerase in chronic myeloid leukemia induced by BCR-ABL in mice. Oncotarget 3:261-266

25. Jones H, Pepper C, Baird M (2012) Telomere dysfunction and its role in haematological cancer. Br. J. Haematol. 156:573-587

26. Boldrini L, Faviana S, Gisfredi Y, Zucconi D (2002) Evaluation of telomerase mRNA (hTERT) in colon cancer. Int J Oncol. 21:493-499

27. Gonza'lez-Sua'rez E, Flores J, Blasco M (2002) Mol Cell Biol 22:7291-7301

28. Rahman R, Latonen L, Wiman G hTERT antagonizes p53-induced apoptosis independently of telomerase activity. Oncogene 24:1320-1327

29. Kanaya T, Kyo S, Hamada K, Takakura M, Kitagawa Y, Harada H, Inoue M (2000) Adenoviral expression of p53 represses telomerase activity through down-regulation of human telomerase reverse transcriptase transcription. Clinical Cancer Research 6:1239-1247

\section{Publisher's Note}

Springer Nature remains neutral with regard to jurisdictional claims in published maps and institutional affiliations.

\section{Submit your manuscript to a SpringerOpen ${ }^{\circ}$ journal and benefit from:}

- Convenient online submission

- Rigorous peer review

- Open access: articles freely available online

- High visibility within the field

- Retaining the copyright to your article

Submit your next manuscript at $\boldsymbol{\nabla}$ springeropen.com 